\title{
Towards an Analysis of Review Article in Applied Linguistics: Its Classes, Purposes and Characteristics
}

\author{
Ali Sorayyaei Azar ${ }^{1} \&$ Azirah Hashim ${ }^{1}$ \\ ${ }^{1}$ English Language Department, Faculty of Languages and Linguistics, University of Malaya, Malaysia \\ Correspondence: Ali Sorayyaei Azar, PhD Candidate, Faculty of Languages and Linguistics, University of \\ Malaya, 50603 Kuala Lumpur, Malaysia. Tel: 603-7967-3177. E-mail: asorayaie@siswa.um.edu.my
}

\author{
Received: June 5, 2014 Accepted: August 25, 2014 Online Published: September 22, 2014 \\ doi:10.5539/elt.v7n10p76 URL: http://dx.doi.org/10.5539/elt.v7n10p76
}

\begin{abstract}
The classes, purposes and characteristics associated with the review article in the field of applied linguistics were analyzed. The data were collected from a randomly selected corpus of thirty two review articles from a discipline-related key journal in applied linguistics. The findings revealed that different sub-genres can be identified within the applied linguistic review article genre. Three main types of review articles were therefore identified based on the analysis of linguistic devices often used by the authors, their communicative purposes, and the specialist informants' feedback: (1) the bibliographic review article which gives readers a comprehensive and descriptive record of annual works and it encompasses the literature-oriented approach, (2) the critical evaluative review article which encompasses subject-oriented approach, that is to say it identifies an idea or raises a research problem, then gives its solution by analyzing and evaluating the selective works done before in the related field, and finally it suggests a new direction, and (3) the mixed-mode review article which has the twin roles and encompasses both literature-oriented and subject-oriented approaches. A possible colony of review genre was suggested and this study further examined some of the characteristics and purposes associated with the review articles. The classification continuum, purposes, characteristics, and linguistic devices of the review articles proposed thus provide useful guidance for graduate EFL (English as a Foreign Language) students and novice writers how to monitor and make use of the review articles during their research writing.
\end{abstract}

Keywords: review genres, academic review genres, review article, critical evaluative review, mixed-mode review, bibliographic review

\section{Introduction}

Review genres are normally written texts or part texts that can provide suitable places for expression of personal ideas, attitudes, and evaluations. It is important to note that authors in review genres are involved in arguing their ideas and expressing their judgment and evaluations. The authors of review genres not only provide an overview and a clear picture of their outcomes based on their own viewpoints but also supply an evaluation of the outcomes and contrast others' viewpoints. As a matter of fact, review genres make a room for the contributors and members in a community to construct a dialogue or an argument so that they could engage with each other through a dialogic interaction and argumentative debates in that room. Review genres might be classified into three groups namely: (a) Art Reviews, (b) Promotional Reviews, and (c) Academic Reviews. In the current study, Academic reviews have been emphasized due to its main focus. One of the key academic review genres that academic researchers need to master is the review article and its classification, categorization, and purposes. It not only provides an overview of works done before in the related field but also evaluates the works and researches skillfully with very critical eyes. In other words, one of the major functions of the review article genre is to evaluate the researches and researchers' contributions. Similarly, it can be stated that academic review genres in comparison with other academic genres are also following literature-oriented and subject-oriented approaches. The former approach provides an overview of the literature in the related fields or sub-fields and the latter one seeks to identify and raise an issue in the research and offers its solution by analyzing and evaluating the contributions, and finally it recommends new directions or trends. It is a fact that Academic Reviews play an important role in the life of academic researchers and scientific community members, and these types of reviews particularly the review article carries out distinctive functions. This type of genre (i.e., the review article genre) is somehow a neglected genre and its contribution has not received more attention in the literature (Hyland, 2000; 
Hyland \& Diani, 2009; Motta-Roth, 1995; Swales, 2004). For all junior researchers and graduate EFL students, whatever their native language, proficiency in academic review genres is an acquired skill.

Maybe it is less obvious that academic review genres including 'book reviews', 'book review articles', 'review of literature sections' in research articles and $\mathrm{PhD}$ thesis, 'book blurbs', and 'review articles' (this classificationisadopted from Hyland and Diani's 2009 'Academic Evaluation' and from Nesi \& Gardner's 2012 'Genres across the Disciplines') also need to be acquired. The main aim of academic review genres is to evaluate the research done before and its developments in that field, and "they assess the value of research and provide a platform for members in a community to engage with each other's ideas and analyses in conventional fora" (Hyland \& Diani 2009, p. 1). Much of the familiarity of junior researchers and graduate EFL students with a basic knowledge in their related field and with the evaluations of the review authors in that field is achieved through the review literature. As Bernal (1948) pointed out a large number of scientists (almost 76 percent) read and appreciated reviews. And also Annual Reviews are the first or second most used sources in the different fields, and as it has been noted "the relatively high impact factor of review journals is well-known" (Garfield, 1987b, p. 118). Let's take another example, in Harris and Katter's (1968, p. 332) study, 'the Annual Review of Information Science \& Technology' was served as the function of main source material for continuing education. But, so far little attention has been paid to the analysis of categorization system, characteristic features, and functions of academic review genres particularly review articles in the field of applied linguistics.

Academic review genres, on the other hand, have been studied extensively over the last decade, in particular the book reviews (Groom, 2009; Hyland \& Diani, 2009; Moreno \& Suarez, 2008; Motta-Roth, 1995), literature review sections in PhD theses (Kwan, 2006; Ridley, 2008; Thompson, 2009), and review articles (Myer, 1991; Noguchi, 2006; Swales, 2004). However, academic review genres still require much more analysis especially review articles.

Among the various types of academic review genre, the review article has attracted the most attention due to its important functions, classification, and characteristic features. It also plays an important rhetorical role in creating a research gap, raising a research problem, and evaluating the works and establishing 'praise and criticism interactions' of authors (Hyland, 2000).

Normally the review article has been understood as a brief survey of relevant literature and this type of review genre has been in circulation since the $18^{\text {th }}$ century (Kronick, 1976, as cited in Garfield, 1987a, p. 113). On the contrary, the review article can be characterized by two major types as stated by Adams (1961), namely (1) discipline review and (2) categorical review. These were two types which belonged to the 19th century German review types. The former is a comprehensive description record, while the latter is a highly selective and critical one and it is focusing on a problem and giving its solution. In another view, Woodward (1974) believed that there can be eight types of reviews, namely critical, evaluation, interpretive, speculative, state of the art, tutorial, historical and popular. Thus, it can be contended that it is not normally a brief survey of relevant literature. For instance, if a review is a critical one it can focus on critical evaluation of published information and ideas. To be short, the review article is a valuable source, as it has been suggested, not only for being an integrative and a synthesized-form scientific article but also for being a source for data access (Garfield, 1987a). As Price (1965) suggested, after publishing thirty or forty research articles in any field we will need for a review. In fact, we can conclude that it is often difficult to give a single definition of a review article because as mentioned above the review article in any discipline and its related fields may take various forms and functions.

With the given definitions and characterizations in mind, there can be more than one function for the review article, namely (1) historical function and (2) contemporary function (Woodward, 1977). It seems that the categorical review article mostly often likes to perform the historical function, while the bibliographic review article which provides merely a survey of the current literature tends to perform the contemporary function (ibid, p. 176). Although there was common agreement that reviews fulfill two primary functions, we can certainly find out from findings of other studies this double role of the reviews obviously needs to be called into question. In publishing reviews there might be significant factors affecting their characteristic features, categorization and functions. Review writers are sought out by editors and solicited to write on a given subject field. The editorial policy, the exact scope and overall format of the journal, the discipline itself, and author's communicative purpose touch on the variation of the reviews. For example, later in Noguchi's $(2001,2006)$ work, the science review article genre has been classified into four main categories namely: (1) history, (2) status quo, (3) theory, and (4) issue. As Swales (2004) pointed out there are no discoursal studies of review articles discussed at length in writing manuals except two: Myers (1991) and Noguchi's (2001) studies. Myers examined review articles of two prominent molecular biologists. It is stated that a review article draws readers into the writer's views of what has happened and by ordering the recent past, it suggests what can be done next (Myers, 1991, p. 46). Neglected 
review genre, as Noguchi (2001) stated in her doctoral dissertation, offers a publishing opportunity, because review articles are more flexible and less frozen than the standard research articles. Her data were 25 science review articles and she has applied textual analysis and the informants' views to the data. Moreover, she suggested review article is a different genre and it is going to become increasingly important as the published literature displays. It is clear that the need for review articles is growing due to situations as pressure to publish, increasing specific fields in different disciplines and the need for their history, and growing the number of scholars. In addition to mastering the academic review genres, junior researchers and graduate EFL students need to raise their awareness of classes, characteristics and purposes of the review articles in the field of applied linguistics. They need to master the linguistic devices used in this type of review genre in terms of categorization system. The review article also plays a significant role for those people in creating knowledge and informing them on how to manage their own learning and how to make use of scholarly reviews. And this is one of the main reasons to justify and show the significance of the current study because there has been scant attention to review article genre in the field of applied linguistics.

In this paper we therefore focus on the abstract and introductory sections of review articles in applied linguistics, to analyze the classification system of the review articles based on the linguistic devices (i.e. textual devices) used and communicative purposes declared by the authors. Our main aim in selecting this academic review genre is to offer a system of classification for the review articles in applied linguistics based on linguistic devices, purposes, intended audiences, and characteristic features. As it has been suggested, the literature review might be classified into its subtypes based on its length, content, subject matter, period cover and expected readership (Manten, 1973). By concentrating on the abstract and introductory sections of review articles, we hope to be able to offer a continuous spectrum perhaps referring to the different types of review articles in this field because it is misleading to classify review articles into distinctive types with certain borderlines by content or subject matter.

The study then suggest a possible colony of review genres and the characteristic features and purposes associated with the review articles in applied linguistics. The findings will also be confirmed by consulting the specialist informants.

\section{Methodology}

The corpus used for this study comprised 32 review articles in the field of applied linguistics, each 18-20 pages on average, published in an established journal between 2000 to 2007 entitled: Annual Review of Applied Linguistics (ARAL printed by Cambridge University Press). The prestige and reputation of this journal in publishing review articles were taken into account and evidentially it has a high impact factor. Yet, another criteria involved in sampling procedure of this study is to consult the specialist informants in that field, this is known as 'informant nomination' the established tradition in sampling and targeting the corpus-based studies (Hyland, 2000, 2007; Kuhi \& Behnam, 2010; Kuhi, Yavari, \& Sorayyaei, 2012). They were asked to name the most prestigious journals with higher degree of reputation among academics in which their review articles were published. A simple random sampling was used to select the corpus. This study was a part of PhD Thesis (at the Faculty of Languages \& Linguistics, University of Malaya, Malaysia) investigating the review articles in applied linguistics (forthcoming).

The first step was to identify and analyze the textual/or linguistic devices including reporting verbs, clauses, phrases, the content itself, and structures referring to the communicative purposes of authors (e.g. Therefore what I wanted to do was..., The main aim of this chapter is...) in the abstract and introductory sections of the corpus. By concentrating on the textual devices of these sections of the corpus, we wanted to investigate the categorization system (i.e. types and classification system), purposes, and characteristic features of the review articles in applied linguistics. Such an analysis of the textual/ or linguistic devices is a necessary prerequisite to the investigation of possible classification variables in this type of academic review genre. In this study, two sets of clues were used to investigate the classification variables and purposes of this review genre: textual devices and the specialist informants' feedback.

In the second step, we referred to the specialist informants through e-mailing interview and personal communication. The main concern of the current research is the discourse community in the field of applied linguistics; therefore it is essential to look inside the academic discourse community in order to learn about the discourse structure, categorization and classification system, purposes and characteristic features of the review articles. For this reason a few semi-structured questions related to the informants' published review articles were asked through personal communication and emailing. These questions were in terms of their main aim of writing and publishing this type of academic review genre in ARAL journal and also clarifying the categorization system, functions and purposes, and characteristic features of the review articles. The specialist informants' feedback and 
replies can be considered as a great guide to our research and it could also be a kind of means to validate the findings of this research.

\section{Results and Discussion}

\subsection{A Classification Continuum of Review Article in Applied Linguistics}

Based on the findings of our analysis of textual devices, many of the reviews did not just summarize published works but they evaluate the works as well. So they could be either evaluative or descriptive. The review articles in the field of applied linguistics in this research were classified into three types namely: (a) critical evaluative review (i.e. this kind of review as its name implies puts much more emphasis on critical evaluation of published work and it encompasses the subject-oriented approach), (b) bibliographic review (i.e. this kind of review gives readers a comprehensive descriptive record of annual works in that field and it encompasses the literature-oriented approach), and (c) mixed-mode review (i.e. this type of review has the twin roles, that is to say this review encompasses both the approaches mentioned above to varying degrees). So far, it seems to us that this type of classification of review articles in the field of applied linguistics has not been done in any research, and also the classification 'labels' are not often used by any authors. It should be added that there are some linguistic devices often used by review article authors to refer to this classification. These textual/ or linguistic devices (i.e. lexical words, phrases, or clauses which have signaling functions) were found to be numerous in the Abstract /or Introduction sections of the review articles studied. Some examples follow:

1) My purpose in this contribution is to look into this question of applicability...My concern, in particular is with L2 learners...At issue is the extent to... (Rev A1, Introduction, Critical Evaluative Review)

2) In this article, we argue that...we begin this article with a brief account...we then discuss the question of...next we explain what Web 1.0 and emerging Web 2.0-based technologies are...we then go on to illustrate how... we conclude with a discussion of some important caveats... (Rev A30, Intro., Critical Evaluative Review)

3) This chapter is about what went wrong and where we might go from here. The discussion first identifies three reasons why initial efforts at partnership may have been...I then argue that... (Rev A5, Abstract, Critical Evaluative Review)

4) This chapter seeks to question this well-established distinction by investigating what is in fact the most common use of English in Europe...The chapter suggests a different way of conceptualizing the language... (Rev A25, Abstract, Critical Evaluative Review)

5) Although there are many studies on the new international norms..., there are limited discussions on the ways local values and identities are negotiated. After reviewing the debates on the place of the local in ELF, this chapter goes onto address the new policy challenges for local communities... (Rev A26, Abstract, Critical Evaluative Review)

6) This chapter is intended to survey these recent developments and highlight some potentially fruitful areas for future research. First $\underline{I}$ summarize some general theoretical and research methodological advances, then $\underline{I}$

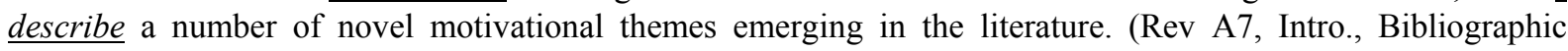
Review)

7) This chapter reviews the literature on psycholinguistic aspects of language attrition over the past half-decade... (Rev A8, Abstract, Bibliographic Review)

8) This chapter takes note of the longstanding orientation Systemic Functional Linguistics (SFL)... The chapter then reviews recent developments and current trends in SFL... (Rev A11, Abstract, Bibliographic Review)

9) This chapter provides an overview of approaches within corpus linguistics...the chapter concludes with $\underline{a}$ brief overview of some other foci in $\mathrm{CL}$ and suggests that ...: the need for more computer tools.... and the need for further studies... (Rev A12, Abstract, Bibliographic Review)

10) This chapter will review the recent research in listening instruction. The first section will provide a brief overview of the cognitive processes...The next section will review recent research on ...The third section will examine two approaches to listening instruction and consider an integrated model... The final section proposes future research directions for... (Rev A17, Intro., Bibliographic Review)

11) This chapter presents a survey of recent developments... and then it discusses current issues and future challenges. (Rev A4, Intro., Mixed-mode Review)

12) ... in this chapter, I proposethat...I describe the anatomy and ...then $I$ propose to showhow it may

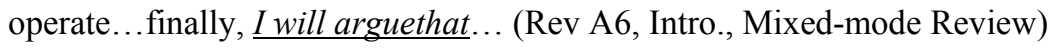


13) This review sketches and offers bibliographical guidance on ....and indicates past or potential points of contact with applied linguistics. After covering these areas, we include a brief discussion of some key themes in...Finally, we discuss several established areas of applied linguistic work in...We end with some cautions on applying CA findings to other applied linguistic research contexts. (Rev A9, Abstract, Mixed-mode Review)

14) This review discusses research published within a relatively brief time span (1998-2002) regarding language maintenance situations in order to illuminate the range of proactive investigation at the time of this writing. (Rev A14, Intro., Mixed-mode Review)

15) This chapter surveys developments in language revitalization, a movement that dates approximately from the $1990 \mathrm{~s}$ and builds on prior work...it discusses the role and nature of appropriate linguistic documentation...Various avenues for language revitalization... are then described...Recent examples of current literature... are reviewed. (Rev A15, Abstract, Mixed-mode Review)

16) The purpose of this chapter is to survey longitudinal SLA research published in the last three years and offer a critical reflection of best current longitudinal practices and desirable directions for future... (Rev A22, Abstract, Mixed-mode Review)

In the examples (1-16), the underlined linguistic devices are used to present and show the authors' intentional position and their main objective of establishing the orientation of the review articles. By using these linguistic devices, the authors try not only to tell the intended audiences why the review articles have been written, but also to refer to the type of the review articles in this field. The devices including 'clauses', 'phrases' and 'reporting verbs' like: 'My purpose is to look into this question..., My concern is..., We argue that..., We discuss the question of...,We conclude with a discussion of..., This chapter is about what went wrong..., This chapter seeks to question.... We include a brief discussion of..., After reviewing the debates...this chapter goes on to address the new policy challenges...' are used to refer to 'Critical Evaluative' text types (examples 1-5). In this study, the authors of the reviews use these linguistic devices to construct an argument for the views or the issues. The $25 \%$ of the reviews involve the critical evaluative review article ( 8 out of 32). As Hyland (2000) noted, "report verbs do not simply function to indicate the status of information reported, but the writer's position in relation to that information" (p.38). This is evident in an academic review genre particularly the review article, where we have found that there is a widespread occurrence of reporting verbs such as 'argue', 'discuss', and 'seek to question' in the review articles in applied linguistics. Similarly, examination of the science review articles in Noguchi's (2006) study revealed that different sub-genres might be identified within the science review article genre. Moreover, it showed that 'issue reviews' are presenting a phenomenon and pointing to some research issues involving it and then offering a solution. Her study clarified that the text types in 'issue review' and 'theory review' are discussing issues or theories in the field.

In addition, the verbs, phrases, and clauses like: 'This chapter presents a survey of ..., This chapter is intended to survey these recent developments..., This chapter reviews..., I describe that..., This chapter provides a brief overview of..., I summarize...then I describe...' are used to refer to 'Narrative and Descriptive' text types(examples 6-10). This category of the review article has been classified as 'Bibliographic review' in this study because it may have been more frequently describing the background of the field or its sub-fields and its current position. The authors use these linguistic devices to present a survey of the works done before, give an overview of the subject, and aware researchers of the present activity in that field. The $25 \%$ of the text types in the corpus of this study belongs to narrative and descriptive text types (8 out of 32). Likewise, 'history review' and 'status quo review' were somewhat showing the same features and characteristics in science review articles (Noguchi, 2006). She clarified that the text types in the two reviews are narrative and descriptive and they are describing history or current work.

In some other examples (11-16), we found integrated signs of the linguistic devices referring to mixed-mode design of text types. In the first example (11), for instance, the author tries firstly to present a survey of recent developments and secondly discusses the recent issues in the field. In the example (16), the author first surveys the recent research and next he/she offers a critical reflection and desirable directions at last. As shown here, the review articles in the field of applied linguistics do not just summarize the published works. Sometimes they may evaluate the issues. And sometimes they might follow both modes (i.e. a mixed-mode design). In this case, they not only present an overview but also discuss and evaluate the views or issues. The degree of intensity from descriptive to critical text type varies from one review article to another due to its focus, function, and author's communicative purpose. The fifty percent of the review articles in this research involve mixed-mode reviews (16 out of 32) and the rest of the reviews belongs to both classes, that is to say, the rate of distribution for the two classes (as shown above) is the same. According to the findings, this category seems to be a unique one in 
applied disciplines in comparison with non-applied areas, particularly science reviews. As it has been shown there has not been such a category in Noguchi's (2006) work.

The findings of this research suggest that we can supply useful criteria for evaluation of review publications. Based on this approach, we can formulate a continuum of classification for this type of academic review genre (i.e. review article genre). This continuum can demonstrate the functionality variation among review articles whether they function as evaluative review or descriptive and indicative review. And also it shows variety of the text types as well as the intended audiences of the reviews. This vertical continual spectrum demonstrates the degree of criticality among the text types of the review articles in applied linguistics (see Figure 1).

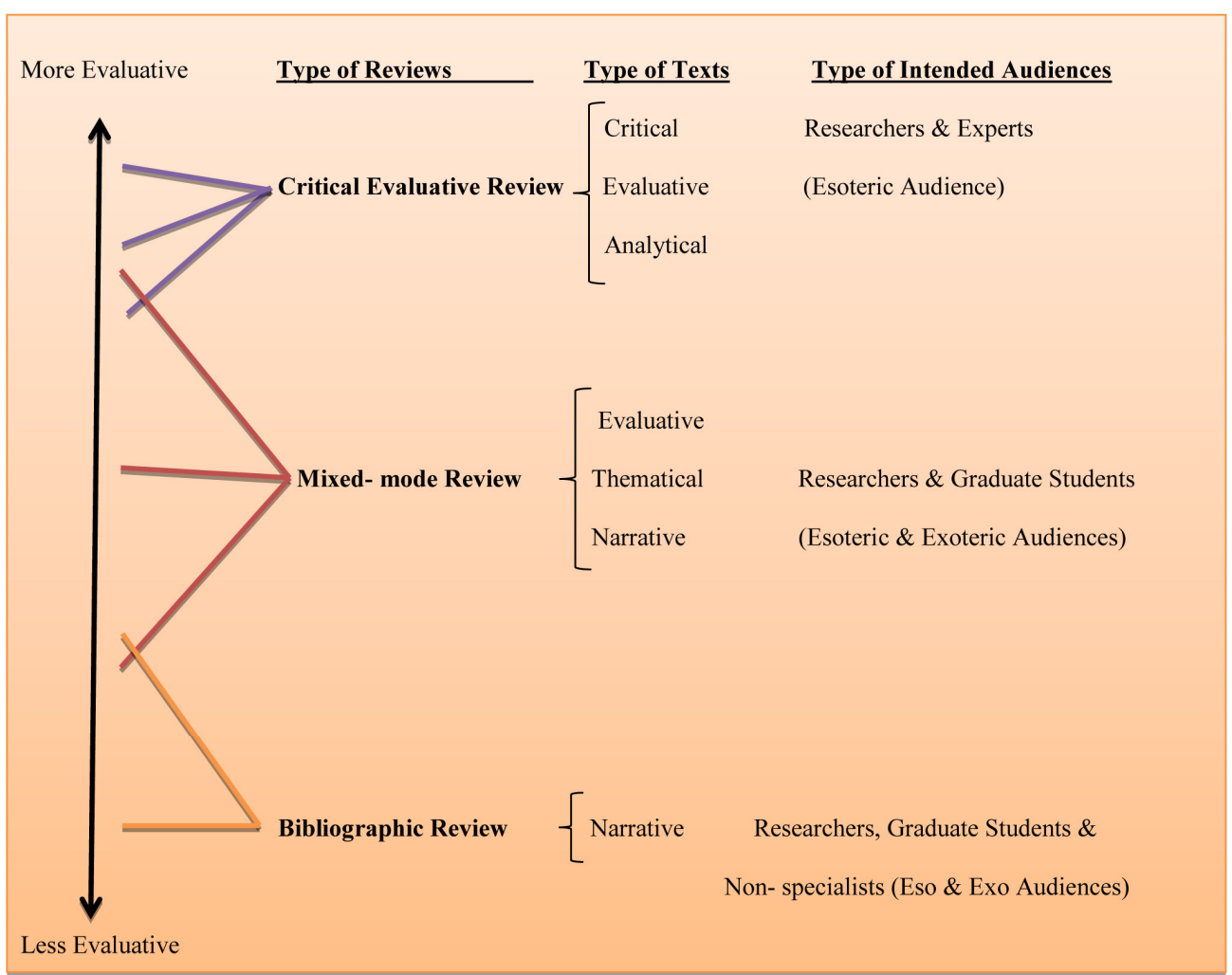

Figure 1. A classification continuum of review articles in applied linguistics

In the figure above, a continuum of review articles in applied linguistics is presented. It has been packed based on the findings of this research, so this continuum is ranging from the bibliographic review through the mixed mode to the critical evaluative review. These reviews, in fact, differ from each other in the kind. Actually the less evaluative and more narrative form is the bibliographic review. From this one if we go up the continuum, we could proceed through a review following a mixed-mode design (i.e. narrative and evaluative texts mixed) and encompassing both approaches. Finally we could reach a critical evaluative review. This type of review seeks to question and discusses the question, analyzes and evaluates the recent developments, reviews and compares the debates, and offers possible solutions and suggests new directions. This type of review article has offered comprehensive, timely collections of critical evaluative reviews written by solicited expert members of the discourse community. Clearly as it has been demonstrated in the figure above, if we proceed this continuum from down to up, we could find out that the text types at the lowest range are less evaluative and more literature-oriented and then it proceeds through a narrative, thematically written text and evaluative type of texts (a mixed- mode text types) to more analytical, evaluative and critical text types.

The findings of the first stage of our study point to similarities and divergences across such sub-genres, based on analyzing and identifying a set of linguistic devices and features targeting the review articles in applied linguistics. The results reveal that these three types of review articles in the field of applied linguistics differ from each other in the kind and their functions. They often occupy their own ideal areas in the continuum expressing on the one hand their intended audiences and variation in authorship and, on the other hand, variation in criticality of the text types based on their communicative purposes. In other words, critical evaluative intensity 
seems to depend on the rhetorical functions, characteristics, and purposes of the review article genre.

\subsection{Characteristics and Purposes of Review Article in Applied Linguistics}

In this section, we have tried to look at the various uses and characteristics of the review articles in Applied Linguistics. So, the characteristics and functions of the review articles were examined and they were further investigated by consulting the specialist informants who were corresponding authors of the reviews in ARAL journal.

Each of the various classes of the review articles in Applied Linguistics seems to carry out different functions and they may have different characteristics, although they might have some purposes in common. The critical evaluative review article is written with critical and evaluative eyes of the author and its value relies on the expertise of the author. The author tries to evaluate the opinions and attitudes in that field or subfields and he/she intrudes himself/herself in the review. This type of review is significant due to the validity of his/her point of view. The text type in this review is argumentative, evaluative, and critical. This review is selective and useful because it neglects to act merely as annotated bibliographies and as a booklet of abstracts. So, the need for this type of review is real due to its significant analysis and evaluation of the author. This review is written by one of the parent members of the discourse community in his/her own field. It requires greater intellectual effort and the expertise of the author. The critical evaluative review article serves four main purposes, they intend to: (1) become subject-oriented, (2) survey the selected works and to raise an issue in the related field, (3) announce the strong point of view in order to reject the opponent's position and analyze and evaluate the opinions in the related field, and (4) suggest a new direction or trend. The intended audiences of this type of review are the researchers, experts, and parent members of the discourse community in that field.

The bibliographic review article is dealt with a limited subject area. All work published in a certain period of time should be included. The analysis of the review articles shows that there are varieties of the text types. In the bibliographic review, the text type is narrative and it may consist of a summary of findings or it can be indicative (i.e. merely in narrative form) or informative (i.e. providing an overview from a variety of publications in that subject with little criticism). As Virgo (1971) states this type of review has "brief notes of findings or opinions, with little criticism and usually without analysis" (p. 277). The intended audiences of this type of review are researchers and graduate EFL students. There are four main purposes for the bibliographic review article, they intend to: (1) become literature-oriented, (2) raise awareness of researchers and graduate students in their own present activity and related field, (3) inform the missing work in that field, and (4) give an overview of the subject.

The mixed-mode review article is intended to play twin roles and written by an outstanding expert in the field. It encompasses both literature-oriented and subject-oriented approaches. The author tries to provide an overview of the related field, or sub-field and then evaluates the developments. In this kind of review article, we have found a degree of intensity between narrative text type and critical evaluative text type. Sometimes the author intends to present an overview of recent developments and then he/she discusses the recent issues in that field, or the author first prefers to argue and raise an issue in that field and then he/she describes a brief overview and surveys the developments and finally the author recommends his/her suggestion.

As it has been shown above, it is difficult to arrive at a single characteristic or description of a review article in applied linguistics due to its various forms, classes, and functions. They sometimes intend to show integrative functions as mixed-mode reviews or critical evaluative functions as critical evaluative review articles or literature-oriented functions as bibliographic review articles. Most of the scholars in analyzing the functions of the review genres like Cozzens (1981), Garfield (1987), Mazella and Malin (1976), Mulrow (1987), Myer (1991), Noguchi (2006), and Woodward (1977) found that junior researchers and graduate students use the review genres as a device to improve scientific knowledge in the related field by using well-documented ways of exploration, synthesizing, evaluation, and giving suggestion as a solution and new direction. Thus, it has become difficult for novice researchers and graduate students to keep up with the primary literature in the related field without consulting the review article because of its role in connecting them with the broader scientific knowledge in applied linguistics.

In the second phase of this research, we further investigated the characteristic features and purposes of the review articles in applied linguistics by consulting the specialist informants in the field of applied linguistics who were the solicited authors of the reviews in ARAL journal. Some of the questions that have been posed via face to face interview or e-mail interview are: (1) What is a review article? And how do you elaborate its functions in the field of applied linguistics? (2) What are the purposes of a review article?, (3) What are the features to be considered to publish an effective review article?, and (4) Who are the intended audiences of the review articles 
in applied linguistics? Their feedback was found to be significant in our study. It is important to note that the feedback received from the specialist informants might be referred to as qualitative data. This type of qualitative data is considered as a source of confirmer for the findings of this study. Some feedbacks follow:

1) A review article is a critical overview of what has been published on a specific topic over a certain period of time. The purpose is to allow novice and experienced readers to see what the main trends are, who has published what, what the focal points are, and what methodology the authors used in their studies. This can be helpful to direct attention to studies of interest without having to read all of them. As researchers often lack time to browse journals and books, this type of publication saves time. (Informant '1', 2012, e-mail interview)

As the first informant's view suggests, the main focus of a review article is to look at the research critically and it intends to show the main trends to the experienced researchers and novice writers.

2) Review articles relate current work in an area to previous work, but focus much more on current and recent work- they are a guide to what has recently been done, and what is being done, for readers who want to know much about this: so they are best written by people who are up to date with not only journals, but all research in progress, and recent $\mathrm{PhD}$ work: they are most useful because they categorize, and distinguish between categories of work in an area, giving the reader a schema to organize and interpret all the things on a topic they read: they are selective, choosing to report in some detail studies, and research questions typical, and most significant, for the categories of the areas they aim to cover- though they do use a lot of bracketed references to refer the reader to citations of work not described in detail: they draw tentative conclusions about the current state of findings, whether questions have been resolved, or are in need of more research, and if so, of what kind in what area: the reviewers own personal opinions and preferences are only mildly influential, since these articles aim to represent what is important to many others working in an area: they try to make use of bulleted summaries, where possible, as a way of synthesizing points in a way which is readable, but with broad coverage: they are to some extent open-ended, aiming to point to future work, and issues for research, and in this way they are useful in setting research agendas and programs for future research: they make use of figures synthesizing studies and findings that can be skimmed and quite easily processed, alongside more descriptive text. (Informant '2', 2012, e-mail interview)

The second informant's feedback tries to give us a comprehensive definition of review article, and who their authors are and with what kind of requirements, its purposes, and functions. In the next view given by the third informant, we can find out that how the informant has tried to clarify the functions of a review article in applied linguistics and its focus on that field. He has classified its intended audiences into several main groups (i.e. experts, researchers, graduate students, and less familiar people with the area). Eventually, he has made a distinction between a review article and a review of literature chapter in $\mathrm{PhD}$ thesis and a review of literature section in research articles:

3) A review article summarizes, synthesizes and attempts to give an overall meaning to research, methods, and/or theory in a particular domain of investigation, defined by the article. It often also attempts to point to directions for future research and even point towards a potential trajectory of that work. Sometimes review articles focus on the work of a particular lab or group (usually associated with the author), to show the coherence and scope and direction of that group's work.

Readers may be people already deeply engaged in an area and who want to see another researcher's views and proposals for future directions or those in neighboring fields who want to get up to speed in the area, or people less familiar with the area who want to become acquainted with the major themes and work in the field. Sometimes they are also assigned to advanced classes or graduate seminars.

They are somewhat different than reviews of literature in graduate theses or dissertations where there is the additional function of displaying the candidate's comprehensive knowledge of the field. This additional function means that graduate theses may be less directed and focused in their reviews.

They are also different than the review section of research articles which are very tightly focused on setting up a specific background for the study to be presented. Review articles tell a somewhat focused but more comprehensive picture of lines of research or a general area. (Informant '3', 2010, personal face to face \& e-mail communication)

In the fourth feedback, the informant has emphasized the characteristic features and functions of a review article in applied linguistics. She has referred to the intended audiences of her review article published in ARAL journal: 
4) Review articles, we can state that, give researchers a brief survey of related literature, provide analysis and evaluation, and aid researchers to identify areas that require further research. Its function is to provide a critical overview of what reviewer finds important in the light of what has been published. In the content of the review, the author might include what the main issues are, how they've been researched, what needs further research. The intended audiences of the review articles are both novice and established researchers on the related field (i.e. applied linguistics and its subfields). (Informant '4', 2013, receiving feedback through e-mail interview)

The last feedback, finally, comes from the informant who has acted in our study as one of the informant nomination' sources (see section 2: Methodology). He has recommended us to hit review articles in applied linguistics in ARAL journal as sampling procedure in our genre-based study. He has put much more emphasis on targeting ARAL in this study because we may arrive at a clear understanding of review articles in the field of applied linguistics:

5) The purpose is to further discussion about a topic or about a scholar's contribution in order to determine the current state of the art. Contributions to ARAL are typically reviews of my first kind and a good way of arriving at an understanding of what a review article is would be to read a number of such articles. (Informant ' 5 ', 2011, e-mail interview)

According to the specialist informants' feedback (as given above), it is reasonable to cater for their views as the value system of discourse community members in terms of unique conceptualization of the sub-genre of the review article as to what its characteristic features, classes, and functions should be. The answers provided by the informants of our research are enlightening and help to set in frame the results mentioned above. The informants' answers somehow help to see how the authors have classified their review articles in applied linguistics into three main classes and what the functions and characteristic features of the review articles should be.

\subsection{A Colony of Review Genres}

After the classification of review articles in the field of applied linguistics and examining the informants' views in terms of the characteristic features, classes, and purposes of this type of review genre, the researchers attempt to describe a colony of review genre in this section. To achieve this goal, the hints were taken from Bhatia's colony form. As given the inter-relatedness of review genre in the different levels, the upper levels and lower levels of review genre can be illustrated in a colony form (Bhatia, 2004). This colony (see Figure 2) can display the relationships of the different levels.

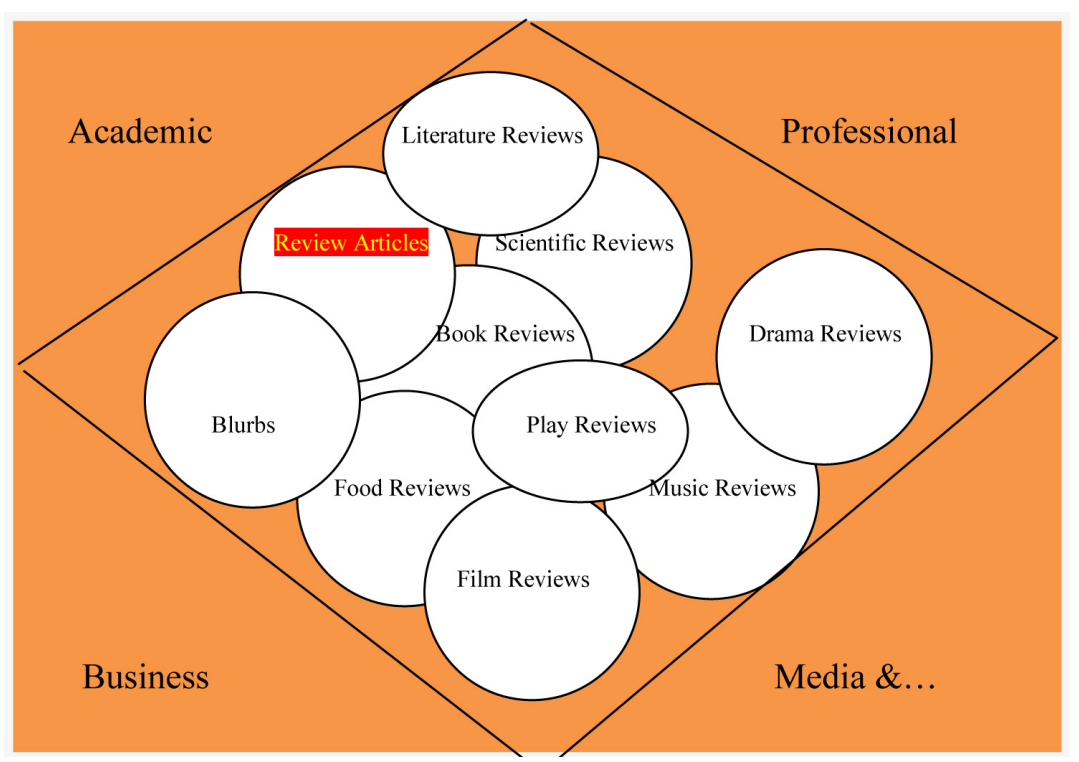

Figure 2. A colony of review genres

The colony shows a group of inter-related genres which they can share their individual communicative purposes. And as it has been mentioned before academic review genre can be classified into five sub-genres (Hyland \& Diani, 2009). But, these sub-genres are different from each other in various respects such as their contexts of use 
(i.e. academic, business, professional, and media contexts are mentioned in the figure above) and audience. The actual social context of review articles, for example, is not the same as blurbs. As shown above (see section 3.1), the intended audiences of the review articles in applied linguistics vary in the kind. Therefore, the intended audiences of the review articles are different groups namely, researchers, junior researchers, graduate students, the discourse community members, and editorial members of the journal. According to Myers (1989), there are more than one type of audience, namely 'an immediate audience' of individual researchers (i.e. esoteric audience) and 'the wider scientific community' (i.e. exoteric audience). For instance, the addressee of 'critical evaluative' review articles are mostly often experts and researchers and this kind of review article is supposed to address 'an immediate audience' of individual researchers (esoteric audience), while the bibliographic review articles seem to address not only researchers as the immediate audiences but also non-specialists and graduate students as well. So, it can be added that the study of genre analysis enables us to make claims about the existence of social factors as envisaged in discourse communities. It is generally believed that a discourse community is a social space with experts at the center and aspiring novices and graduate students at the periphery (Swales, 1990, p. 27).

As it has been pointed out, in the above figure, this genre colony makes genre colonization (Fairclough, 1992 as cited in Bhatia, 2004). Actually, it is a process in which one genre integrates with another genre and in addition it leads to a hybrid form. They can share their own features together and the feature of one genre affects the other genre. In other words, there can be a sign of 'genre-mixing' or 'embedding of genres' (Bhatia, 1997; Sorayyaei Azar, 2012). We cannot find static and fixed borders between in the different levels of these genres. The review genres can represent a group of closely related genres. They can serve to some extent similar communicative purposes, however there is no need to be shared in all of their communicative purposes. In other words, the colony shows "a function of the versatility of the genre" (Bhatia, 2004, p. 59). In the Figures 2 and 3 the colony of review genre is also illustrated. It should be here added that the base notion of the genre colony is adopted from Bhatai (2004).

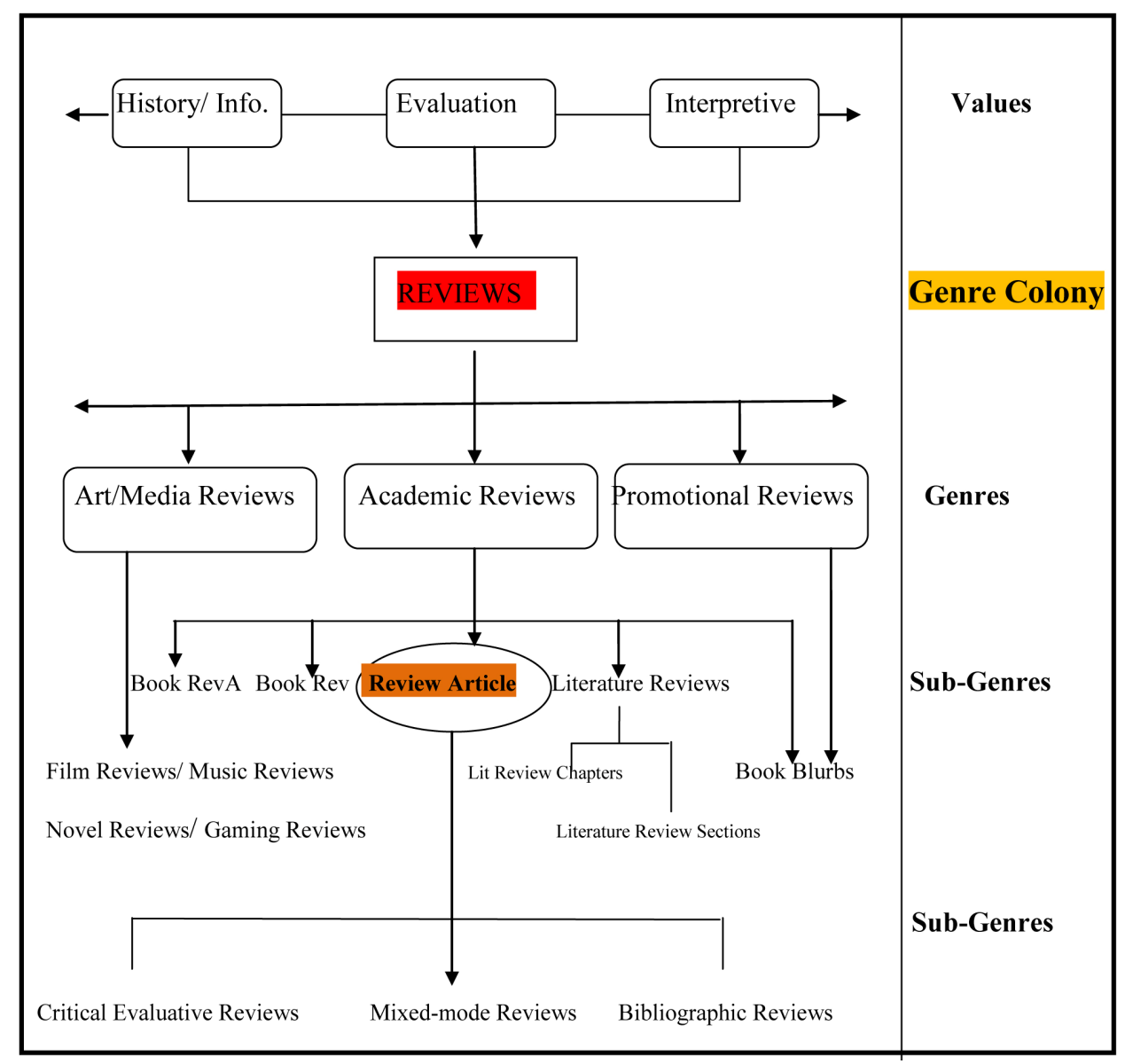

Figure 3. A genre colony of reviews: genres and sub-genres 
In fact, in the figure 3 the colony of review genres can be subcategorized into genres, namely art reviews, academic reviews and promotional reviews. These are genres which are closely related to each other and at least in one value they might be in common. We can notice in the blurb genre, the two genres namely academic and promotional one can be integrated and led to the blurb sub-genre. Or in review article genre, for example, we can find more than one function. It can be not only evaluative and present the writers' stance but it can also be informative giving us a history and informing the missing work in that field and transform much more data about the current work or theory, just like literature review. The review article itself, as shown above, can be classified into various kinds of review articles based on the functions they represent and carry out, namely critical evaluative review, bibliographic review, and mixed-mode review. As a result, the findings of the current study reveal that different sub-genres could be identified within the applied linguistic review article genre. According to Noguchi's (2006) study and Swales' (2004) suggestion, this type of review genre can be classified into historical or bibliographic review, issue review, current work review and theory review. The findings of our research are focused on the review article in applied linguistics with three main classes, while Noguchi's study and suggestion has been emphasized the science review article with four types. Or according to Woodards' (1974) classification, reviews in humanities and scientific fields might be critical, evaluative, interpretive, state-of-the art, historical and tutorial. Thus, it seems that even if review authors and journal editorial members in different disciplines share expectations that this academic review genre will be in different categorization and characteristic features, there is a general variation in the field and its community members with respect to the function and its classification continuum of review articles. We can suggest from the present study that the disciplinary variable, the value system of scientific community members, the editorial policy and exact scope of journals, and the authors' beliefs, ideologies, and communicative purposes influence the degree of categorization and characteristic features of review articles and thus the primary function the review articles fulfill.

\section{Conclusion}

In this study we firstly attempted to investigate the classes, characteristic features, and purposes of the review texts in applied linguistics selected from 32 randomly selected review articles that were published during 2000-2007 in ARAL journal, and compared the findings with those that are posited in Noguchi's (2006) work for sciences review articles. It is found that there are three main types of review articles in the corpus of this research namely: (1) the bibliographic review article which gives readers a comprehensive and descriptive record of annual works and it encompasses the literature-oriented approach, (2) the critical evaluative review article which encompasses subject-oriented approach, that is to say it identifies an idea or raises a research problem, then it gives its solution by analyzing and evaluating the selective works done before in the related field, and finally it suggests a new direction, and (3) the mixed-mode review article which has the twin roles and encompasses both literature-oriented and subject-oriented approaches. The fifty percent of the review articles in this research involve mixed-mode reviews (16 out of 32) and the rest of the reviews belongs to both classes, that is to say, the rate of distribution for the two classes is the same: $25 \%$ of the reviews involve critical evaluative reviews ( 8 out of 32) and $25 \%$ of the reviews involve bibliographic reviews ( 8 out of 32). This stage is based on the analysis of linguistic devices often used by the authors in 'Introduction' and 'Abstract' sections.

Secondly we consulted the specialist informants through personal communication and e-mail interview in order to look inside the value system of the discourse community. The second stage acted as a confirmer to our findings in the current research. This approach considered review articles on a continuum of classification ranging from the bibliographic review through the mixed-mode review to the critical evaluative review. This analysis in this study also indicates that the review articles in applied linguistics are characterized according to the author's beliefs and communicative purposes, the intended audiences, editorial policy and exact scope of the journal. And also in this study it is shown how colony of review genre may be developed through the specification of the review functions and values.

There is variation too across the disciplines: for example in biology science, the majority of the review articles, as it has been suggested, are classified into four categories (Noguchi, 2006). Or let us take another example, the review articles in Biomedical Engineering (IEEE Reviews in R-BME) might be of two main types according to the statement of editorial policy: (1) Methodological Reviews, and (2) Clinical Application Reviews. The former is to present a critical review of current methods, while the latter one is to present a critical review of methods applied to a current clinical problem.

It is hoped that a closer understanding of the categorization system, characteristic features, and linguistic devices used by the authors to signal the classes and functions of the reviews in a given context may help uncover elements of the value system that emphasizes disciplinary discourse, while providing graduate EFL students and novice writers with the ability to make use of scholarly reviews and primary sources during their research 
writing. Writing instructors are also advised to teach the textual strategies applied in the review articles in their English for academic purposes (EAP) classes. This will raise the awareness of graduate EFL students and novice writers of the categorization and characteristic features of the review articles so that they can be familiar how to monitor the review article genre.

Eventually, it is vital to acknowledge limitations to our study. It would have been better if a different discipline had been chosen in order to do a comparative study. The review articles in this corpus are all from applied linguistics and are not from non-applied areas, so the findings of this research need to be tested on review articles from other disciplines, particularly hard sciences so that EAP or ESP instructors can take advantage of the findings in their Seminar and Research Writing classes for hard science graduate students.

\section{Acknowledgements}

First, we express our profound gratitude to the specialist informants for their invaluable hints and comments, which really guided us to the goal of this research. The authors are also very grateful to the editorial team of English Language Teaching for giving us helpful comments.

\section{References}

Adams, S. (1961). The review literature of medicine. Bibliography of medical reviews, 6.

Bernal, J. D. (1948). Preliminary analysis of pilot questionnaire on the use of scientificliterature. Royal society scientific information conference, 46, 589-637.

Bhatia, V. K. (1997). Genre-mixing in Academic Introductions. English for Specific Purposes, 16, 181-195.

Bhatia, V. K. (2004). Worlds of written discourse: A genre-based view. New York: Continuum.

Cozzens, S. F. (1981). User requirements for scientific reviews. Report paper no. 20.

Fairclough, N. (1992). Discourse and Social Change. Cambridge: Polity Press.

Garfield, E. (1987a). Reviewing review literature, Part I. definitions and uses of reviews'. Essays of an Information Scientist, 10, 113-116.

Garfield, E. (1987b). Reviewing review literature, Part II. the place of reviews in the scientificliterature. Essays of an Information Scientist, 10, 117-122.

Groom, N. (2009). Attribution and averral revisited: Three perspectives on manifestintertextuality in academic writing. In P. Thompson (Ed.), Patterns and perspectives: Insightsinto EAP writing practice (pp. 14-25). Reading: CALS, the University of Reading.

Harris, L., \& Katter, R. V. (1968). Impact of the Annual Review of Information Science and Technology'. Proceedings of the American Society for Information Science Annual Meeting, 5, 331-333.

Hyland, K. (2000). Disciplinary Discourses: Social Interactions in Academic Writing. London: Longman.

Hyland, K. (2007). Applying a Gloss: Exemplifying and reformulating in academic discourse. Applied Linguistics, 28(2), 266-285.

Hyland, K., \& Diani, G. (2009). Academic Evaluation: Review genres in University settings. Hampshire: Palgrave Macmillan.

Kuhi, D., \& Behnam, B. (2011). Generic variation and metadiscourse use in the writing ofapplied linguistics: A comparative study and preliminary. Written Communication, 28(1), 97-141.

Kuhi, D., Yavari, M., \& Sorayyaei Azar, A. (2012). Metadiscourse in applied linguisticsresearch articles: A cross-sectional survey. Mediterranean Journal of Social Sciences, 3(11), 405-411.

Kronick, D. A. (1962). History of scientific periodicals (1665-1790). Metuchen, N.J.: ScarecrowPress.

Kwan, K. (2006). The Schematic Structure of Literature Reviews in Doctoral Theses of Applied Linguistics. English for Specific Purposes, 25, 30-55.

Manten, A. A. (1973). Scientific review literature. Scholarly Publication, 5, 75-89.

Mazella, A., \& Malin, M. (1976). A bibliometric study of the review literature. Report paperno, 94.

Moreno, A. I., \& Suarez, L. (2008). A study of critical attitude across English and Spanishacademic book reviews. Journal of English for Academic Purposes, 7(1), 15-26.

Motta-Roth, D. (1995). Same genre, different discipline: A genre-based study of book reviews in academe. The ESPecialist, 17(2), 99-131. 
Mulrow, C. D. (1987). The medical review article: State of the science. Ann. Intern. Med., 106(3), 485-487.

Myers, G. (1989). The Pragmatics of Politeness in Scientific Articles. Applied Linguistics, 10, 1-35.

Myers, G. (1991). Stories and styles in two molecular biology review articles. In C. Bazerman, \& J. Pardis (Eds.), Textual dynamics of the professions. Madison: University ofWisconsin Press.

Nesi, H., \& Gardner, Sh. (2012). Genres across the disciplines: Student writing in highereducation. Cambridge: Cambridge University Press.

Noguchi, J. T. (2001). The science review article: An opportune genre in the construction ofscience (Unpublished $\mathrm{PhD}$ dissertation). The University of Birmingham, UK.

Noguchi, J. T. (2006). The science review article: An opportune genre in the construction of Science. Bern: Peter Lang.

Price, D. J. D. (1965). Networks of scientific papers. Science, 149, 510-515.

Ridley, D. (2008). The literature review: A step by step guide for students. London: Sage.

Sorayyaei, A. A. (2012). The Self-Promotion of Academic Textbooks in the Preface Section: A Genre Analysis. Atlantis, revista de la Asociación Española de Estudios Anglo-Norteamericanos, 34(2), 147-165.

Swales, J. (1990). Genre analysis: English in academic and research settings. Cambridge: Cambridge University Press.

Swales, J. (2004). Research genres: Exploration and applications. Cambridge: Cambridge University Press.

Thompson, P. (2009). Literature reviews in Applied PhD Theses: Evidence and problems. In K. Hyland, \& G. Diani (Eds.), Academic evaluation: Review genres in University settings. Bern: Peter Lang.

Virgo, J. A. (1971). The review article: Its characteristics and problems. The Library Quarterly, 41(4), 275-291.

Woodward, A. (1974). Review literature: Characteristics, sources and output in 1972. AslibProc., 26, 367-376.

\section{Copyrights}

Copyright for this article is retained by the author(s), with first publication rights granted to the journal.

This is an open-access article distributed under the terms and conditions of the Creative Commons Attribution license (http://creativecommons.org/licenses/by/3.0/). 